\title{
¿Cómo hacen investigación los trabajadores sociales? \\ Una primera aproximación a las experiencias de investigación de una generación de profesionales chilenos
}

\author{
How research is done by social workers? \\ A first approach to the research experiences of a \\ generation of Chilean professionals
}

\author{
María Gabriela Rubilar \\ María Gabriela Rubilar es (C) Doctor por la Universidad Complutense de Madrid, actualmente es académica de la Escuela de \\ Trabajo Social, P. Universidad Católica de Chile. Su dirección postal es Av. Vicuña Mackenna 4860, Macul - Campus San Joaquín. \\ Su correo electrónico: grubilad@uc.cl
}

\begin{abstract}
Resumen
En este artículo sintetiza los resultados de una investigación que analizó el quehacer investigativo de un grupo de trabajadores sociales chilenos, titulados entre 1995 y 2005.

Se asume como punto de partida de este trabajo, que el quehacer de los trabajadores sociales se encuentra estrechamente vinculado con prácticas investigativas, que desde distintos caminos complementan y enriquecen el desarrollo profesional.

El estudio se realizó siguiendo las directrices del método biográfico interpretativo, lo que hizo posible la construcción de una tipología que identifica tres perfiles profesionales, diferenciados de acuerdo al modo cómo los trabajadores sociales se aproximan a la investigación social y la forma como la desarrollan.

Estos perfiles, constituyen un primer paso en la construcción de una tipología de investigación en Trabajo Social, dado que fueron elaborados a partir de las identidades de los profesionales que participaron en este estudio, la que se espera continuar profundizando con aportes provenientes de otras investigaciones.
\end{abstract}

Palabras claves. Práctica Investigadora - Método biográfico/interpretativo -Investigación SocialQuehacer profesional.

\begin{abstract}
This abstract analyzes the investigation developed by a group of Chilean social workers graduated between 1995 and 2005. It is assumed -as a starting point- that, though this investigation constitutes a field that is still developing for this profession, the social workers' work is closely linked with investigative practices which, through different ways, complement and nurture the professional development.

The study of the social workers' research was carried out following the guidelines of the biographical interpretation method. This allowed the construction of a typology that identifies three professional profiles which are differentiated according to the way in which the social workers get nearer to we social investigation and to the way in which it is developed.

These profiles constitute a first typological construction because they were drawn up starting from the professionals' identities who participated in this investigation. This investigation is expected to deepen thanks to contributions coming from other investigations.
\end{abstract}

Key words. Investigative practices -biographical interpretative method- social investigation workers work. 


\section{Introducción}

\section{El sentido de una indagación del oficio inves- tigativo de los trabajadores sociales}

Reconociendo que la articulación entre investigación e intervención, constituye en una preocupación de larga data para el Trabajo Social, este artículo muestra qué hay más allá de la tensión inicial ${ }^{1}$, qué puentes o conexiones se producen entre investigación y acción social, y el modo como ésta se expresa en determinadas actuaciones.

El trabajo se inicia constatando que la preocupación en torno a la relación entre investigación e intervención estaba presente, aunque con otras denominaciones, en los primeros escritos de la profesión ${ }^{2}$. En el contexto latinoamericano, algunos autores como Grassi (1995), Kisnerman (1998), Heler (2002) y Matus, Aylwin y Forttes (2004) plantean que, desde el inicio del Trabajo Social, los profesionales han hecho investigación, pero ésta suele encontrarse encapsulada o silenciada. Y, por lo mismo, se desarrolla en forma marginal o desde ámbitos que cuentan con escasa difusión e incidencia pública. Desde esta perspectiva, la investigación no sería antagónica a la intervención, sino más bien una dimensión a potenciar y complementar, reconociendo con ello el carácter complejo de ambos procesos y sus múltiples interrelaciones ${ }^{3}$.

Este planteamiento, encuentra entre sus fundamentos un supuesto central, que este artículo aborda cuando se propone desentrañar el modo cómo hacen investigación los trabajadores sociales. Constituyéndose en la pregunta guía de esta investigación, que toma como referente inicial una serie de escritos y publicaciones que abordan la historia del Trabajo Social y que señalan que, desde sus orígenes, los trabajadores sociales han contado con instrumentos y herramientas orientadas a conocer e indagar en las en problemáticas sociales que afectan a determinadas personas y colectivos ${ }^{4}$.

El diagnóstico social, la visita domiciliaria, el informe social y la entrevista sociofamiliar son instrumentos metodológicos presentes desde el inicio de la formación de los trabajadores sociales. Estas técnicas, que fueron impulsadas con el propósito de objetivar, obtener evidencia, y asignar un carácter científico a la asistencia social (Richmond, 1917), han sido reinterpretadas en el transcurso del desarrollo de la profesión, alcanzando hoy en día distintas aproximaciones según los enfoques o perspectivas que las sustentan ${ }^{5}$. Desde la perspectiva de esta investigación, estos instrumentos tradicionales de intervención profesional, presentan importantes similitudes con algunas de las técnicas e instrumentos utilizados en la investigación social, especialmente aquella que se desarrollan desde un enfoque cualitativo. La observación, la conversación, el uso de técnicas narrativas ${ }^{6}$, se encuentran a la base de estas aproximaciones que, aparentemente, persiguen propósitos distintos.

Callejo y Viedma (2005) en una publicación reciente dan cuenta precisamente de esta relación, al profundizar en las orientaciones actuales de la investigación y los alcances que la investigación puede lograr desde la perspectiva de la intervención social. Especial atención brindan en su trabajo

1 Por lo general, los debates y discusiones sobre esta cuestión suelen abordarse desde dos polos: uno, dedicado a conocer, describir e interpretar; y el otro dedicado a la acción. Desde una mirada tradicional cada polo se opone al otro, percibiéndose como una tensión que hace que los profesionales del Trabajo Social se ubiquen preferentemente en el plano de la acción, dejando de lado la generación de conocimiento.

2 En los años 20, la estadounidense Mary Richmond (1917 y 1922) planteaba la necesidad aplicar técnicas e instrumentos que permitieran asignar un carácter científico a la asistencia. Unas décadas antes, en España, Concepción Arenal asumía una posición similar en su libro La beneficencia, la filantropía y la caridad, publicado en 1894.

3 Los planteamientos de Daniel Bertaux reafirman lo anterior cuando señala "... lo social no es fijo; es político y "opera" bajo la presión de fuerzas contrarias y cambiantes. Si estructura el campo de la praxis, es a su vez el objeto, el foco de la praxis. Una sociología que no se limitara a analizar el orden establecido, sino que tratara de aprehender las contradicciones que dicho orden engendra y las transformaciones estructurales resultantes, debería esforzarse por unificar el pensamiento de lo estructural y el de lo simbólico, y sobrepasarlos para llegar a un pensamiento de la praxis" $(1999$, p. 6).

4 Matus, Aylwin y Forttes en La reinvención de la memoria, señalaron que desde sus inicios como profesión, el Servicio Social cuenta con "una tradición escrita, donde existen narrativas, modelos y formas de registro de sus intervenciones y donde se le asigna tempranamente un papel de relevancia a la investigación social" (2004, p. 28). Sus argumentos coinciden con los planteamientos de Haluk Soydan (2004) y Carlos Marchevsky (2006)

5 Desde distintas posiciones, autores como Karsz, 2007; Mazzola, 1998; Seden, 1999; Vass, 1986, dan cuenta de estos elementos como componentes esenciales de la habilidades y competencias de los trabajadores sociales.

6 Especialmente entrevistas. Constatando que a las ya tradicionales orientaciones entregadas por Mary Richmond (1917 y 1922), le han seguido una serie de manuales y compendios entre los que se destacan los trabajos recientes de Cáceres, Oblitas y Parra, 2000; Rosell, 1989; y Travi, 2006, por sus especificidades para el Trabajo Social. 
a las conexiones entre proyectos de investigación e intervención, aportando nuevas reflexiones metodológicas en el campo de la investigación-acción e investigación social participativa, así como en el diseño de investigaciones que combinan técnicas diversas de recopilación y análisis de información. Sus argumentos encuentran importantes similitudes con los planteamientos desarrollados por el norteamericano Donald Shön (1983 y 1987) quien dos década antes, analizó las prácticas de los trabajadores sociales, centrando su investigación en la forma cómo los profesionales aprenden. Al estudiar el quehacer de los trabajadores sociales, Shön ${ }^{7}$ descubrió que en el Trabajo Social hay una distancia entre la teoría y la práctica profesional, como la hay en toda situación donde la teoría analiza aquello que llamamos realidad.

Tomando en cuenta lo señalado por Shön, esta investigación concibe la relación entre investigación y Trabajo Social como una realidad con múltiples interconexiones y significaciones. Y es desde esta posición, que se analiza de manera exploratoria, las vinculaciones que los profesionales establecen entre investigación y acción profesional, y los significados que le atribuyen. La investigación se desarrolló siguiendo las directrices y orientaciones que proporciona el enfoque interpretativo ${ }^{8}$, dado que se consideran que las visiones y concepciones que los profesionales tienen de la investigación social, son dependientes de las interpretaciones que tienen los sujetos participantes en este estudio, incluidas las visiones de la autora de esta investigación?.

Desde este enfoque se entiende que la propuesta tipológica que se ofrece en el cuerpo principal de este artículo es una interpretación, entre otras, que avanza en la construcción de perfiles o tipologías profesionales. Otras lecturas son posibles, y desde ya queda abierta la invitación a pensar en otras posibilidades que contribuyan a la reflexión disciplinar en torno a la relación entre investigación y Trabajo Social ${ }^{10}$.

\section{Las opciones metodológicas de esta investigación: El enfoque histórico biográfico, los testimonios de investigación y la identificación de una tipología.}

Siguiendo como lineamiento central la pregunta ¿Cómo hacen investigación los trabajadores sociales? se desarrolló una práctica investigadora, cuyos resultados se suman a aquellas posiciones que dan cuenta de la existencia de interconexiones entre las herramientas e instrumentos que los trabajadores sociales utilizan en sus actuaciones profesionales y determinadas técnicas de investigación social.

Se optó por analizar en profundidad el quehacer investigativo de un número acotado de trabajadores sociales con el propósito de estudiar y analizar las prácticas de investigación que estos profesionales han desarrollado; la formación recibida en este ámbito; los enfoques y perspectivas metodológicas utilizadas en el desarrollo de sus investigaciones, así como la valoración de los alcances asignados a su trabajo. Del mismo modo, se analizaron las motivaciones que les llevaron a estudiar la carrera, la forma como conciben la relación entre investigación e intervención, y en el modo cómo articulan los conocimientos allí generados a su quehacer profesional ${ }^{11}$.

El enfoque histórico biográfico fue la propuesta metodológica utilizada para el desarrollo de esta investigación, cuyo principal referente investigativo fue la construcción de ocho testimonios de

7 Este autor plantea en su trabajo que el estudio de la práctica profesional es un reto para la investigación, en la medida que los profesionales utilizan en su quehacer una mezcla de acciones, ideas, retazos de diversas teorías, habilidades personales, adaptaciones a las situaciones particulares, entre otros elementos (Shön, 1983). Plantearse el estudio de las prácticas investigativas de los trabajadores sociales significa, de alguna forma, asumir este desafio, al intentar develar un ámbito de la profesión oscurecido por creencias, debates, polémicas y tensiones hasta ahora no resueltas.

8 Al respecto Claudio Ramos señala: "en el paradigma interpretativo las relaciones estudiadas remiten más bien a entrecruzamientos de eventos, a secuencias de procesos históricos” (2005, p. 108).

9 Este posicionamiento se hace tomando la sugerencia formulada por Denzin y Lincoln (2005) acerca de la conveniencia de iniciar una investigación haciendo un reconocimiento de los condicionamientos históricos y socioculturales del investigador.

10 En este contexto, resulta especialmente significativas lo escrito por Juan Francisco Marsal (1979) en Pensar bajo al Franquismo, cuando reconoce el carácter condicionado de su análisis, y por lo mismo invita al lector a formular sus propias interpretaciones.

11 Específicamente con esta investigación se esperaba: (1) Indagar en la formación investigativa de los trabajadores sociales, analizando el papel que ha jugado la formación a lo largo del desarrollo profesional; (2) Conocer su quehacer investigativo, analizando el modo como hacen investigación, los enfoques o perspectivas utilizadas, el tipo de conocimiento generado, así como las técnicas e instrumentos privilegiados en este labor; y (3) Analizar la forma como se dan las interacciones entre intervención e investigación desde el Trabajo Social. 
investigación de trabajadores sociales titulados de una universidad chilena entre 1994 y $2005^{12}$. Este enfoque que articula dimensiones sociales e individuales extraídas de los testimonios, permite abordar el problema de la investigación desde la narración de la propia historia profesional, donde el relato es comprendido en sí como una expresión identitaria, ya que implica un trabajo de construcción y reflexión sobre sí mismo y sus circunstancias.

Este enfoque ha tomado una fuerza inusual en las últimas décadas, producto de una serie de trabajo publicados a inicio del 2000 entre los que se destacan las aportaciones de Prue Chamberlayne, Johanna Bornat \& Tom Wengraf, 2000; Tom Wengraf, 2001 ${ }^{13}$; Gabriele Rosenthal 2004; Kip Jones 2004, entre otros ${ }^{14}$

Pese a su actual vigencia, en esta investigación el acercamiento histórico-sociológico se sustenta básicamente en las orientaciones metodológicas entregadas por Daniel Bertaux a principios de los 80 , que buscaban hacer visible, a través de testimonios, las coordenadas histórico-biográficas de los participantes en la investigación. Además de las aportaciones de este autor, el énfasis otorgado al método biográfico sigue esencialmente las tradiciones de las historias de vida de William Thomas y Florián Znaniecki (1919); William Whyte (1953); Oscar Lewis (1961 y 1964), y Juan Francisco Marsal (1979). De igual forma, se consideraron las orientaciones metodológicas que brindan practicantes contemporáneos del método biográfico en Hispanoamérica, como Juan José Pujadas (1992), Ana Lía Kornblit (2004), y Miguel Valles (2006 y 2007).

Para el análisis de las prácticas investigadoras y la construcción de los perfiles sociobiográficos, se siguió la tradición investigativa de los testimonios escritos, en directa vinculación con los relatos e historias orales (Lejeune, 1994). Siete de los ocho testimonios presentados fueron elaborados a partir de entrevistas cualitativas, mientras que el testimonio restante siguió la tradición de las autobiografías o autoentrevistas, en la línea propuesta por ReedDanahay (1979), Boufoy-Bastick, (2004) y Miguel Valles (2006)

La identificación de regularidades al interior de cada testimonio y entre los testimonios fue lo que hizo posible la construcción de tres perfiles de trabajadores sociales, diferenciados a partir del modo cómo estos profesionales conciben y hacen investigación social. Cada perfil se configura a partir de un eje o tópico central, desde el cual se despliegan elementos y rasgos que le caracterizan: El primer perfil posee como componente central los procesos de toma de decisiones de políticas sociales, y es desarrollado en su mayoría por consultores y expertos quienes recurren a la investigación para orientar las actuaciones públicas. El elemento central que caracteriza a los profesionales que integran el segundo perfil es precisamente la investigación y el interés que han demostrado estos trabajadores sociales por dedicarse profesionalmente a ella. A diferencia del perfil anterior, en el tercer y último perfil, será la intervención la que determina el modo y la forma como se desarrolla el quehacer investigativo.

\section{Una propuesta de análisis con tres perfiles de trabajadores sociales}

Las primeras referencias que evidenciaron la existencia de rasgos o elementos diferenciadores entre los entrevistados, surgieron al momento construir los testimonios autobiográficos ${ }^{15}$. Fue en esta fase donde emergieron los primeros elementos y relaciones que conforman una tipología que identifica tres perfiles de profesionales. Cada perfil daría cuenta de un modo o forma de entender y hacer investigación desde el Trabajo Social.

12 Utilizando entrevistas biográficas, se construyeron los testimonios de investigación de ocho trabajadores sociales, titulados en una de las primeras Escuelas de Trabajo Social del país que impartió la Licenciatura en Trabajo Social, con ello ampliando la formación investigativa de sus egresados. Sus testimonios y experiencias de investigación se constituyen en el principal material empírico utilizado en esta investigación, que recurre a un número acotado de casos para analizar en profundidad una experiencia o quehacer determinado.

13 Especial relevancia adquiere en esta investigación el trabajo de Tom Wengraf, quien ha utilizado el enfoque biográfico en el estudio de las prácticas de profesionales. Su estudio publicado en el año 2004 con el título "Boundaries and Relationships in Homelessness Work: Lola, an Agency Manager" analiza el quehacer profesional de una administradora de servicios sociales y los conflictos que ella enfrenta en su labor, realzando el papel de las experiencias personales en sus investigaciones.

14 La mayor parte de estos autores utilizan una técnica de entrevista que consiste en una sola sugerente pregunta narrativa inicial (pasiva, minimalista), para provocar una extensa e ininterrumpida narración.

15 Las entrevistas fueron trabajadas bajo el formato de testimonios, siguiendo esencialmente las orientaciones de edición proporcionadas por Miguel Valles, el que toma como referente el trabajo de Oscar Lewis (1973), quien a propósito de la preparación de su libro Los hijos de Sánchez, escribió: "al preparar las entrevistas para su publicación, he eliminado mis preguntas y seleccionado, ordenado y organizado sus materiales en autobiografías congruentes [0]". Con ello se sigue una tradición ya iniciada por Allport en 1942, quien señalaba que las autobiografías podían ser, además de completas, temáticas y corregidas” (en Valles, 2008, p.20). 
Antes de presentar los rasgos que caracterizan a cada perfil, se considera conveniente precisar que los perfiles sociobiográficos no son tipologías puras, sino más bien, el encadenamiento de un conjunto de visiones y concepciones en torno a la investigación social que van conformando un modo de hacer de los trabajadores sociales. Hay, por tanto, perfiles mixtos y, posiblemente más posibilidades que las que se exploran inicialmente en esta investigación ${ }^{16}$.

Por lo mismo, se reitera en este estudio que los tres perfiles identificados son más bien aproximaciones iniciales, en torno a los cuales es posible continuar investigando, y de ellos deviene su carácter inacabado. El último de los perfiles es el que presenta mayor imbricación (o indefinición) y por lo mismo es una construcción sujeta a revisión y análisis en una siguiente etapa de investigación. Tampoco existe una relación unívoca entre los testimonios y los perfiles identificados, de hecho es posible encontrar testimonios que responden a tipos mixtos ${ }^{17}$ o que combinan rasgos que pertenecen a más de un perfil.

Las diferencias se establecen con mayor claridad entre los profesionales de Trabajo Social que corresponden a un perfil, que denominamos "experto" y aquellos trabajadores sociales cuyo quehacer se asemeja más a un investigador en formación, cuyo perfil hemos denominado "investigadores académicos". El tercer perfil tuvo distintas apelaciones en el transcurso de la investigación, lo que denota desde un principio la dificultad de nombrar una categoría que sigue siendo imprecisa ${ }^{18}$.

A continuación se delinean los rasgos que caracterizan y conforman cada uno de los perfiles, siguiendo un esquema que intenta responder a las preguntas directrices planteadas al inicio de esta investigación: ¿Qué hacen los profesionales que se identifican con este perfil? ¿Qué los caracteriza o diferencia de otros profesionales de Trabajo Social? ¿Cómo y desde qué referentes conciben la investigación? y ¿Cómo hacen investigación?

\section{Perfil uno. Expertos, analistas y asesores de políticas sociales}

La primera imagen que se puede vincular a este perfil que hemos denominado "experto" se asocia con un tipo de profesional que se desempeña en funciones de analista o asesor en temas o problemáticas de interés público. Siguiendo el testimonio de los entrevistados, este perfil se correspondería mejor con un tipo de profesional, especializado en una temática o problemática social que le vuelve en algún sentido experto ${ }^{19} \mathrm{o}$ informante clave ante otros investigadores y decidores públicos.

Por lo general, la autoridad de estos profesionales ha sido forjada a partir de su experiencia profesional ${ }^{20}$, que se constituye en una plataforma privilegiada para la observación y análisis de fenómenos sociales concretos. Por lo mismo su experticia posee una dimensión práctica, que los entrevistados reconocen con claridad.

Se autoconciben como operativos de ideas, por su capacidad de plasmar y poner en marcos de posibilidad, los planteamientos y decisiones de los directivos. En su quehacer profesional, suelen desarrollar un rol de analista, o de apoyo a una dirección o unidad institucional determinada, aportando elementos para la toma de decisiones que, articulan tanto aspectos político e institucionales, como dimensiones operativas relacionadas con las propuestas e iniciativas que se esperan implementar.

Entre los rasgos que caracterizan a estos profesionales se encuentra la capacidad de mediar y articular mundos y realidades, que por lo general se encuentran separadas (como las condiciones que enfrentan las personas que viven en situación de pobreza o exclusión social, con las decisiones que respecto de ellos, toman las autoridades políticas o administrativas). Lo que nos remite a un modelo de generación de políticas públicas que combina elementos de un diseño top down, donde las decisiones públicas son tomadas desde arriba hacia abajo; con un modelo bottom up, donde la gestación de alternativas de

$16 \mathrm{Al}$ inicio de este artículo se señalaba que en esta investigación no hay una sola lectura interpretativa. De hecho un mismo actor puede realizar más de una lectura, tal como ha ocurrido en este proceso investigativo cada vez que se revisan los materiales reunidos.

17 La existencia de perfiles mixtos, ya había sido advertida por Miguel Valles en su investigación I+D Medición de la Xenofobia en España (2007c y 2008).

18 Cabe señalar que los nombres de los perfiles que aquí se presentan son provisorios, y sujeto a las revisiones y aportaciones que los propios lectores puedan realizar. Desde ya, queda abierta la invitación a pensar y revisar estas categorías iniciales.

19 En el sentido señalado por Dexter (1970).

20 Los protagonistas de los testimonios uno y dos, son quienes que más se acercan a este perfil. Ambos tienen más de 10 años de experiencia profesional y la mayor parte del tiempo se han desempeñado en la misma temática. Sin embargo, es importante constatar que el tiempo trabajado en un ámbito determinado, no es una condición unívoca para transformase en experto, hay elementos claves para su conformación como la validación por parte de una contraparte o de sus propios pares. 
política se produce desde dimensiones o factores que se encuentran en el origen del problema ${ }^{21}$.

La idea de la mediación, aportada por uno de los testimonios, resultó especialmente interesante al momento de analizar la relación entre intervención e investigación y la forma cómo hacen investigación estos trabajadores sociales ${ }^{22}$. Tomando en cuenta lo anterior, no resulta extraño que los profesionales más vinculados a este perfil, se conciben desarrollando un rol de mediador entre distintos espacios y ámbitos, siempre desde un plano que los entrevistados denominan técnico u operativo, dado que en ellos no recae directamente la toma de decisiones. Por lo mismo, se autodefinen como traductores, puentes o vinculadores para la toma de decisiones de otros.

Si bien, estos profesionales señalan que su labor de apoyo o asesoría se circunscribe a un ámbito esencialmente temático, gradualmente observan que su espacio de influencia se va ampliando, involucrando otros aspectos decisionales, más vinculado a dimensiones políticas o estratégicas de carácter organizacional ${ }^{23}$. Dado lo anterior, los protagonistas de los testimonios uno y dos son enfáticos en reconocer la autoridad e influencia que manejan, la que definen como 'poder tras las sombras'. Estatus que se ha cimentado en buena medida por el dominio que poseen de información y la capacidad de relacionar y anticipar eventos relevantes ${ }^{24}$.

La ambigüedad, la tensión constante y la inestabilidad, son los elementos que caracterizan el quehacer de estos asesores, quienes en ocasiones desarrollan su labor sin contar con especificidades acerca de sus competencias o responsabilidades. Los entrevistados definen su papel como un cargo de confianza y por lo mismo, su estabilidad depende esencialmente del mantenimiento de esta condición en la relación con sus superiores o con quien actúa como contraparte ${ }^{25}$

Por las características de su práctica profesional, declaran estar sometidos a tensión constante, especialmente por la expectativa que se generan acerca de su labor y la necesidad de decir algo interesante. Se asume que, por el cargo o función que desempeñan, poseen una competencia o especialidad que en ocasiones trasciende a su formación inicial. En sus relatos se observa que los fantasmas y amenazas que enfrenta este ser experto están asociados a la temporalidad y futilidad de su rol, que pone permanentemente a prueba a quien lo desempeña ${ }^{26}$

Es precisamente este carácter ambiguo e inestable, que caracteriza el rol de experto, el que determina el modo y la forma como estos profesionales se aproximan y entienden la investigación social ${ }^{27}$. En términos generales se puede afirmar que los trabajadores sociales que integran este perfil:

Tienen una visión parcial de la investigación, por lo general acotada a determinados momentos del proceso (delimitación del problema, criterios para la selección de informantes, revisión de instrumentos y retroalimentación de los resultados y conclusiones). Dado que su contribución se encuentra centralmente circunscrita a lo temático, su participación en las investigaciones es acotada metodológicamente y relevada por su aporte programático.

Delimitan los problemas y definen agendas: desde esta posición de experto, reconocen la

21 De acuerdo a lo señalado por Eugenio Lahera (2002) es posible identificar dos lógicas o racionalidades que han predominado en la implementación de políticas públicas y programas sociales. La implementación desde arriba hacia abajo o modelo top down y las perspectivas de implementación que invierten esta lógica predominante, denominada modelo bottom-up.

22 En este perfil, se observa también que la función mediadora podría ser asimilada a la noción de "personas puente", concepto tomado por Miguel Valles, a partir del trabajo de Richard Sennett (2003: 34), y que corresponde a uno de los tipos estratégicos identificados en el proyecto I+D Medición de la Xenofobia en España (2007, p.15 y 2008. p. 16). [0]

23 A la luz de los propios entrevistados, los expertos son personas informadas, "saben lo que pasa en su tema y en ámbitos relacionados" como ciencias sociales, política, y economía. Articulan sus observaciones con experiencias y aprendizajes de otros países y establecen conexiones entre distintos ámbitos.

24 Los protagonista de los testimonios uno y dos, reconocen que por lo general a un experto 'se le pide una opinión' y por lo mismo, ambos imprimen una perspectiva de análisis estratégico a su quehacer profesional, que les lleva a esforzarse por 'hacer las cosas bien y a poner en práctica lo aprendido'.

25 En este caso la confianza es entendida como lealtad a un proyecto o a unas directrices por lo general de tipo politico o institucional.

26 Reconocen que es una labor solitaria, aunque paradójicamente detrás de cada entrevistado se constata la existencia de un equipo de profesionales, técnicos y recursos que dan sustento a su rol.

27 Del análisis de los testimonios se puede colegir también que existía algo así como un camino de 'hacerse experto', lo que podría explicar el carácter ambiguo de este rol, en la medida que se puede situar a los entrevistados en tránsito o en una dirección que gradualmente los va conduciendo por este camino. 
posibilidad de instalar e insertar, en la agenda de investigación, determinados temas, como resultado del poder que se les atribuye en este contexto, a quienes son identificados como informantes claves. Pos lo mismo, son actores que conocen con detalle la agenda investigadora, a los equipos, investigadores y a los centros de estudio que desarrollan investigación en su respectiva área ${ }^{28}$.

Su visión de la investigación se construye contradictoriamente: se aprecia desencanto con el resultado de las investigaciones en las que han participado, reconocen una cierta instrumentalización de su trabajo, y escasa incidencia de esta en las problemáticas que les atañen. De lo anterior se desprende que la investigación en estos actores es vista como un insumo o respaldo para la intervención a mediano y largo plazo, dado que reconocen que hay urgencias y necesidades que la investigación social no puede abordar con los tiempos y prioridades requeridas.

Se ubican en el polo de las investigaciones aplicadas: principalmente de tipo consultorial, dado que sus trabajos se encuentran vinculados a estudios e indagaciones financiadas por la misma institución donde se desempeñan y cuyos resultados permanecen en la esfera interna. De sus testimonios se desprenden, también importantes críticas a la investigación social base, especialmente cuando observan la distancia que ésta presenta con los contextos y necesidades en los cuales se desenvuelven.

La investigación base la conciben como un reducto de las universidades y de institutos espe- cializados y por lo mismo, sus visiones incluyen importantes observaciones al modo cómo se realiza la investigación en estos organismos, la que es connotada como una comunidad elitista y en algún sentido cuestionada por los fines o propósitos con que ésta se realiza ${ }^{29}$. Es esta visión crítica, la que les lleva a plantear la necesidad de traducir los resultados de la investigación, tanto a los destinatarios como a los directivos públicos. Con ello ponen en evidencia la necesidad de difundir y presentar sus resultados en formatos y lenguajes más accesibles que los que imperan en la investigación académica, reafirmando su concepción como puentes o mediadores de realidades $^{30}$

Si se toman en cuenta estas concepciones, es posible comprender mejor el quehacer de los trabajadores sociales que conforman este perfil. Éstos se apresuran en clarificar que el trabajo que realizan no responde a las investigaciones científicas convencionales. Su labor consiste más bien en realizar estudios breves en ámbitos o temáticas muy determinadas, con reportes recurrentes a quienes los han encargado y con formatos bastante definidos ${ }^{31}$. Este tipo de investigación, que uno de los entrevistados denomina 'investigación de ámbito político-institucional', se desarrolla bajo un esquema que se distancia bastante del modelo de investigación base o investigación académica, que estos profesionales aprendieron durante su formación universitaria. Declaran que el modelo de investigación que desarrollan, presenta más semejanzas con las directrices y referentes investigativos que utilizan las ONGs y consultoras que realizan estudios de opinión y de mercado $^{32}$, con ello reconocen las distancias entre

28 Lo anterior se observa al constatar que desarrollan un seguimiento sistemático de su tema en la prensa especializada y de opinión pública en general.

29 Especial relevancia adquieren sus observaciones acerca de la utilización de las vivencias de las personas pobres o en situación de vulnerabilidad, por parte de investigadores y agencia de investigación. Cuestionamiento que los ubica en el centro de los debates que en torno a este tema se han desarrollado en el país, y que a llevado a organismos como el Fondo Nacional de Desarrollo Científico y Tecnológico (FONDECYT) a la creación, en el año 2005, de un Comité Asesor en Bioética responsable de velar por el cumplimiento de los estándares éticos y bioéticos que regulan la actividad científica y la protección de quienes forman parte de la investigación. Recuperado el 27 de marzo de 2009 de http://www.fondecyt.cl/578/propertyvalue-57382.html.

30 Señalan que los directivos esperan que uno resuma los resultados del trabajo en tres hojas e idealmente vaya acompañado de una presentación en Power Point. Esta visión también es compartida por el FONDECYT, quien en sus sugerencias para escribir un consentimiento informado en estudios con personas señala: "el texto debe ser fácilmente legible, utilizando frases cortas, párrafos breves, evitando términos técnicos y recurriendo a un lenguaje comprensible para personas sin educación científica”. Recuperado el 27 de marzo de 2009 de http://www.fondecyt.cl/578/articles-27522_recurso_1.pdf.

31 En sus reportes se consignan los antecedentes del problema a estudiar, se analizan las alternativas y cursos de asignación y se incluye una opinión o sugerencia a seguir.

32 Las empresas consultoras que realizan estudios e investigaciones surgen en Chile a mediados de los años 80, coincidiendo con el proceso de transición a la democracia y a la redefinición del rol desempeñado por las ONGs hasta ese momento. De hecho, en los 90 un número significativo de Organismos No Gubernamentales formaron sus propias empresas de consultoría y estudio, o se afiliaron a otras para conformar empresas asociadas. 
su trabajo y la investigación académica que se genera en centros especializados y universidades.

Los estudios que realizan, responden a una demanda o requerimiento institucional, y por lo mismo, se mueven en el campo de las investigaciones por encargo y no publicables. Tal vez sea el carácter de estos estudios, lo que explique la invisibilidad de su quehacer investigativo, a tal punto que se vuelve casi imperceptible para los propios entrevistados, quienes declaran que "no saber mucho de investigación" o reconocen importantes debilidades metodológicas en este campo.

El carácter o estatus ambiguo de los expertos, es una condición que afecta también a la investigación que ellos realizan y a la forma como conciben su incidencia. Pese a autodefinirse con poder en la toma de decisiones, presentan problemas al momento de reconocer la incidencia pública de su trabajo investigativo, precisamente cuando se constata o confronta la capacidad de estos personajes para instalar o poner determinados temas en la agenda investigativa. $\mathrm{Al}$ momento de realizar sus investigaciones, ambos profesionales declaran sus preferencias por un enfoque de investigación cualitativo-interpretativo, que relacione contextos y situaciones. Para ello resulta esencial el uso combinado de técnicas e instrumentos de recopilación de información de distintas tradiciones disciplinarias. Entre estas técnicas, cobra especial protagonismo el seguimiento sistemático de prensa y las observaciones directas ${ }^{33}$, que permiten articular y poner en contexto a los distintos actores y elementos estudiados. A la observación en prensa y en los contextos naturales se suma el desarrollo de prácticas conversacionales recurrentes (con distintos actores y a distintos niveles) que permiten a estos profesionales ir contrastando realidades y agregando información para la toma de decisiones. Se conciben especialmente fuertes en este ámbito, capaces de entablar diálogo con otros y a partir de ahí generar propuestas y caminos de análisis.

En su práctica investigadora se constata el uso de preguntas directrices y de provocaciones que movilizan y desencadenan conversaciones, especialmente orientadas a desarrollar esta función mediadora o de puente ya mencionada. Tras sus planteamientos se puede rastrear la idea de estallido conversacional, desarrollada por Jesús Ibáñez, cuando señala: "Una de las cosas que más sorprenden y encantan a los observadores -y a los protagonistas- de un suceso revolucionario, prerrevolucionario o pararrevolucionario, es el estallido conversacional. Todos hablan de todo con todos: se disuelven como azucarillos las barreras que separan a unos de otros y a cada uno de sí mismo (...) Una revolución es una inmensa conversación: un rescate del ser de las garras del valor" (1994, p. 73).

De este modo, vuelve a emerger como un rasgo esencial de este perfil el modo cómo los actores vinculan su investigación con la realidad social, además de la capacidad de conectar elementos y establecer relaciones. Desde sus planteamientos, el análisis constituye una función principal de su labor, lo que explica la alta valoración que los trabajadores sociales que integran este perfil le asignan a las herramientas e instrumentos analíticos, y la necesidad de profundizar y completar su formación en este ámbito, que incluye además de las herramientas en boga de investigación social cualitativa y cuantitativa, temas de gestión y el análisis estratégico.

\section{Perfil dos. Investigadores en formación}

El segundo perfil agrupa a aquellos profesionales que desarrollan principalmente labores relacionadas con el quehacer científico-investigativo, por lo general, circunscrita a contextos académicos e institutos de investigación. Integran este perfil aquellos trabajadores sociales que se encuentran cursando estudios de postgrado o que tenían inquietudes de desarrollar una formación en este ámbito ${ }^{34}$. Es importante precisar, que los profesionales que más se identifican con este perfil, presentan una formación mixta que combina Trabajo Social con otras disciplinas ${ }^{35}$, situación que les ubica en un punto intermedio entre dos tradiciones profesionales, cuyas interconexiones hacen posible la generación de categorías más abstractas y la ampliación de las perspectivas con las cuales se concibe el quehacer profesional. No obstante su formación híbrida, se sienten y se autodefinen como

33 Además del seguimiento de prensa, son herramientas esenciales para estos profesionales la observación y las entrevistas. La primera es concebida por lo general desde una tradición etnográfica y antropológica, aunque no siempre vaya acompañada de un sistema de registro sistemático, por su parte las entrevistas que desarrollan estos profesionales suelen seguir dos tradiciones: una más periodística que recuerda las aportaciones de Mayhew (citado en Valles, 2002, p. 12) y otra que sigue la orientación de las entrevistas focalizada, atribuida a Merton y Kendall (1946).

34 Serán los protagonistas de los testimonios tres y cuatro, los que se asocian más directamente con este perfil. Aunque es posible encontrar varios de los elementos que le caracterizan en el quinto testimonio.

35 Por lo general en Sociología, aunque el protagonista de uno de los testimonios poseía una licenciatura vinculada a las artes. 
trabajadores sociales, encontrando en este caso con una identidad profesional reafirmada, en un sentido inverso a la identidad deteriorada, desarrollada por Goffman en su trabajo publicado originalmente en 1963.

Del análisis de sus testimonios se observa que la investigación forma parte de su quehacer profesional. La posición que ocupa la investigación en su trayectoria profesional se constituye en el principal elemento diferenciador de los profesionales que integran los otros perfiles, quienes visualizan la investigación como un componente que complementa, y en algunos casos tensiona, su acción profesional.

Su educación ha tenido un marcado acento investigativo. Durante su formación universitaria mostraron preferencias por las cátedras que abordaban estas temáticas y colaboraron tempranamente en investigaciones y estudios de profesores. El desarrollo de esta opción investigadora ha implicado la generación de una serie de estrategias y mecanismos que les permiten ubicarse en un oficio investigador ${ }^{36}$.

Los profesionales que se vinculan a este grupo tipológico, experimentaron un tipo de inserción laboral que resultó reveladora en la definición de su trayectoria profesional. Su incorporación a centros académicos y de investigación vinculados a una universidad, les posibilitó el desarrollo de prácticas de trabajo interdisciplinarias y de articulaciones entre docencia, investigación y extensión ${ }^{37}$. Es en este contexto, donde se aproximan y aprenden una forma distinta de hacer investigación, que amplía los horizontes y referentes adquiridos durante su formación universitaria. Es en este ámbito, donde los trabajadores sociales, logran evidenciar con mayor claridad las articulaciones y conexiones que se producen entre investigación e intervención, lo que marca sus concepciones futuras y el modo como éstos se aproximan a la investigación social.

En sus testimonios van a reconocer la existencia de una serie de limitaciones y obstáculos para el desarrollo de un quehacer investigativo en Chile, que incluyen tanto interpelaciones a la forma como se hace investigación en el país ${ }^{38}$, así como elementos que constituyen el imaginario tradicional de la profesión, que no concibe que los trabajadores sociales se dediquen exclusivamente a la investigación.

Declaran expresamente que les gusta hacer investigación y que esperan dedicarse profesionalmente a ello. Así mismo, reconocen la necesidad de completar su formación y desarrollar una práctica en este ámbito que, les permita validar los conocimientos y competencias aprendidas, e incorporar nuevas perspectivas y referentes investigativos. A lo anterior se suma, que los profesionales que integran este perfil han desarrollado o esperan desarrollar estudios de postgrado en el extranjero, logrando formas y acercamientos investigativos, que complementan y profundizan sus aproximaciones iniciales. Tomando en cuenta lo anterior, es posible afirmar que los estudios de postgrado constituyen una alternativa para concretar este proyecto, dado que los profesionales van constatando que esta opción investigadora es compleja de materializar únicamente con una formación de licenciado ${ }^{39}$.

Desde el inicio de su formación profesional, los trabajadores sociales que más se vinculan con este perfil, se han ido formando como investigadores, participado primero como ayudantes o becarios, muchas veces ad honorem o en forma voluntaria, para luego ir asumiendo otras funciones y roles ${ }^{40}$. De ahí la idea de noveles investigadores, cuando se constata que, quienes integran este perfil, han ido

36 En términos generales se constata que los trabajadores sociales, que conforman este perfil, poseen una experiencia profesional distinta a la mayoría de sus compañeros de generación, quienes suelen centrar su quehacer en torno a la intervención social.

37 Dos entrevistados desarrollaron sus primeras actuaciones profesionales en programas y centros que realizan extensión, investigación y docencia en temas de salud. Las vinculaciones entre salud y Trabajo Social, se pueden rastrear desde el origen de la profesión. Las primeras Escuelas de Visitadoras Sociales en Latinoamérica surgen bajo el alero de centros de beneficencia pública y de filantropía privada que prestaban una labor esencialmente sanitaria e higienista (Matus, Aylwin y Forttes, 2004).

38 En la visión de integrantes de este perfil, la investigación en Chile se acota a un grupo de actores determinados y a una comunidad investigativa relativamente pequeña. Visión que presenta coincidencias con los resultados de un estudio elaborado para CONICYT en el año 2004, que señalaba que en el país habían 15 graduados de doctorado por cada millón de habitantes y algo así como 3 investigadores cada mil empleados. En este mismo informe se consigna, que en el año 2004 la inversión en I+D que se destina no superaba el 0,7\% del PIB. Recuperado el 30 de marzo de 2009 de http://www.conicyt.cl/573/article-7399.html. El sistema bicentenario Becas Chile, recientemente impulsados por el gobierno pretenden revertir esta situación, formando capital humano en el extranjero, con una meta estimada de 30 mil profesionales en 10 años. Recuperado el 30 de marzo de 2009 de http://www.becaschile.cl/que_es/

39 En el relato de los testimonios tres y siete se observan elementos que denotan una cierta frustración ante un escenario laboral que se ofrece como posible, pero cuya concreción es relativa, lo que se traduce en un quiebre de expectativa con el proyecto laboral inicialmente forjado.

40 En este caso, se suma la protagonista del testimonio cinco, quien ha desarrollado actuaciones similares en este ámbito. 
desarrollando un camino de formación en investigación, en el que gradualmente van asumiendo mayores responsabilidades y tareas, lo que les permite una cierta validación como investigadores ante sus pares y otros profesionales del ámbito social.

Como se ha señalado, la experiencia profesional de estos trabajadores sociales es diferente a la de sus compañeros de generación, y por lo mismo son enfáticos en afirmar que en su quehacer profesional han realizado una opción profesional que toma a la investigación como principal campo de desarrollo. Desde su perspectiva, la investigación se concibe como un ámbito de trabajo, que fue descubierto durante su formación profesional, iniciando un camino que ha permanecido en el tiempo.

Por su acercamiento al tema, los profesionales que integran este perfil poseen concepciones particulares sobre la investigación social, a la que conciben como:

Un ámbito esencial de su quehacer profesional: los integrantes de este perfil se autoconciben profesionalmente haciendo investigación. Dado lo anterior, la investigación es considerada una dimensión central y en algún sentido omnipresente de su desempeño profesional. En consecuencia con ello, a futuro, se ven investigando ${ }^{41}$.

Poseen una visión crítica de la investigación: En sus testimonios ponen énfasis en las trabas y dificultades que existen para hacer investigación en el país, a la vez que emergen algunos cuestionamientos a la forma como se concibe y hace la investigación social ${ }^{42}$. En forma complementaria, uno de los entrevistados, da cuenta de la falta de elementos teóricos y conceptuales que sustenten la investigación que se genera desde el Trabajo Social, así como la existencia de menor rigurosidad en sus planteamientos metodológicos. De sus argumentos se desprende que, en la investigación de Trabajo Social habría una sobrevaloración de aquellos estudios que desarrollan una indagación empírica, en detrimento de las formulaciones teóricas o conceptuales, lo que incidiría directamente en su desarrollo como disciplina. Desde su perspectiva, se vuelve relevante la necesidad de pensar la investigación en Trabajo Social como un fenómeno en sí y no en función de la intervención social o de problemas sociales específicos

Al mismo tiempo reconocen:

La necesidad de aumentar la complejidad de las investigaciones que realizan ${ }^{43}$ Sus argumentaciones dan cuenta de la necesidad de repensar la secuencia con la que se hace investigación desde el Trabajo Social y reafirman la importancia de desarrollar análisis más sofisticados, tanto para aquellas investigaciones que se desarrollan bajo un enfoque cuantitativo, como las que se construyen desde un enfoque cualitativo. Es en este contexto que uno de los entrevistados plantea también la necesidad de romper con una secuencia de investigación que se inicia con la delimitación de un problema y finaliza extrayendo conclusiones y sugerencias, por lo general orientadas a la intervención, y avanzar en la el desarrollo de otras posibilidades investigativas.

Fortalecer la formación investigativa de los trabajadores sociales: Los integrantes de este perfil valoran positivamente aquellas apuestas educativas orientadas a hacer más robusta la formación en investigación de los trabajadores sociales, no obstante reconocer la existencia de algunas dificultades y limitaciones, particularmente en la forma como la investigación se presenta a los estudiantes $^{44}$. Observan, además, que las dificultades que presenta la investigación de los trabajadores sociales no serían muy distintas a los obstáculos que encuentran quienes hacen investigación social en Chile, con la diferencia que los trabajadores sociales presentarían mayores

41 Por lo general vinculados a un centro de estudios o a un espacio académico, que les permita concretar este proyecto. Esta visión también se encuentra presente en la protagonista del testimonio cinco, en cuyo horizonte profesional, la investigación se sigue presentando como una aspiración futura.

42 La dimensión ética, también emerge en sus relatos, aunque en un sentido distinto a lo expresado en los testimonios del primer perfil, dado que además de poner acento en los sujetos que forman parte de la investigación, se cuestionan los fines y propósitos con los que se usan los resultados de algunas investigaciones así como el manejo de recursos de grandes proyectos.

43 Sus argumentos presentan importantes coincidencia con las hipótesis explicativas desarrolladas por Claudio Ramos a propósito de la falta de complejización de la investigación sociológica en Chile (2005, p. 102 y 103).

44 Como una tarea en extremo compleja y difícil de concretar, al menos en el corto plazo, dado que el principal referente de investigación es aquella que se produce a nivel de investigación base y que es financiada mediante concurso público. El Concurso Regular FONDECYT se constituye en un icono al respecto, dado que desde el año 1981 financia vía concurso investigaciones básicas en ciencia y tecnología. 
dificultades al momento de escribir y publicar los resultados de sus trabajos.

La importancia de analizar las interacciones entre investigación e intervención: Como se ha señalado, para algunos de estos profesionales, la investigación en Trabajo Social presenta como riesgo el tema de la utilidad o aplicabilidad, al considerar que se suelen forzar sus conexiones o vinculaciones con los procesos de intervención. No se aprecian acuerdos en este ámbito, dado que en otros testimonios se valora precisamente esta vinculación, concibiéndola como uno de los rasgos característicos del tipo de investigación que se desarrollaría desde el Trabajo Social ${ }^{45}$.

De lo anterior se observa, que existen aproximaciones y visiones distintas sobre la investigación entre los trabajadores sociales que integran este perfil, lo que podría constituirse en un rasgo característico de estos profesionales a quienes hemos concebido en proceso de formación como investigadores.

El modo o forma como hacen investigación, tiene directa relación con sus experiencias investigadoras, que como se ha señalado, se han forjado a partir de ayudantías y becas de colaboración académica. Por lo mismo, su quehacer investigativo se encuentra acotado a momentos determinados de un proceso de investigación (delimitación del problema, criterios para la selección de informantes, revisión de instrumentos y retroalimentación de los resultados y conclusiones). En sus inicios, se observa que estos profesionales apoyan en la elaboración de bases de datos; elaboran y aplican instrumentos (pretest, encuestas, entrevistas); realizan cruces preliminares de resultados, a partir de un plan de análisis pre definido. Su labor se concentra esencialmente en la fase de elaboración de instrumentos y recopilación de información, y por lo mismo, es concebida como una participación parcelada, en la cual se pierde la globalidad del proceso investigativo.

Se han vuelto en algún sentido "expertos" en la aplicación de técnicas e instrumentos y poseen menor experticia en el análisis, dado que esta es una tarea por lo general reservada a los investigadores principales. Son ellos los que proveen de insumos y elementos para que otros analicen. Y por lo mismo, no resulta extraño que uno de los aspectos más débiles de su quehacer se encuentra en la redacción de informes y publicación de los resultados de sus investigaciones.

Son estas colaboraciones y ayudas, las que les van aproximando al oficio de investigador y les permiten ir desarrollando una práctica en este ámbito. En este proceso van acumulando experiencia; completan los vacíos detectados en su formación; y definen algunos lineamientos y ámbitos temáticos en torno a los cuales proyectar su quehacer. En sus itinerarios profesionales se observa que, progresivamente, asumen mayores responsabilidades y participan en procesos de toma de decisiones de aspectos sustantivos de los proyecto de investigación en que participan

Su labor investigativa y en buena forma sus intereses, se centran en temas emergentes y poco explorados en el ámbito social, donde la investigación se concibe como un elemento esencial para la generación de conocimiento y en un insumo para la intervención, como ocurre por ejemplo con el fenómeno migratorio. Se observa que poco a poco van delimitando sus intereses y competencias en temas y enfoques específicos lo que podría ser el germen de una futura línea de investigación. De lo anterior se desprende la idea que este segundo perfil sería, al menos en esta fase de formación, más generalista y con capacidades investigativas más amplias, que el perfil uno, que en algún sentido se encuentra especializado temáticamente. Ante esta distinción, cabría preguntarse si alguno de los profesionales, que hoy en día se asocian con el perfil dos, podría llegar a trasformarse en experto, y terminar desarrollando una labor más similar a la que caracteriza a este primer perfil ${ }^{46}$.

Si bien, los trabajadores sociales que más se vinculan con este perfil declaran su preferencia por desarrollar investigaciones bajo un enfoque cualitativo, reconocen que no tienen dificultades en el abordaje de enfoques cuantitativos, dado que declaran poseer una excelente formación de base en estadística y un manejo avanzado de programas informáticos de procesamiento de datos. En su quehacer, se observa también, cómo van incorporando a su quehacer investigativo, prácticas y enfoques de otras disciplinas como el análisis jurídico y la perspectiva que ofrecen los estudios culturales y de

45 Este elemento, que también abordan los otros testimonios, se constituiría en otro de los rasgos que caracterizan transversalmente el quehacer investigativo de los trabajadores sociales.

$46 \mathrm{Al}$ inicio de este artículo se señalaba la existencia de perfiles mixtos, agregando ahora la posibilidad de interconexiones al interior de cada perfil. 
género, que se sustentan desde un paradigma eminentemente interpretativo.

Lo que habría detrás de esta polivalencia de enfoques y perspectivas, es precisamente el interés de estos profesionales por ir desarrollando una práctica investigadora (ir aprendiendo el oficio), lo que cobra especial sentido cuando se constata su necesidad de hacer entrenamiento investigativo, de poner en práctica técnicas y herramientas de investigación diversas así como tradiciones investigativas distintas. Lo anterior se comprende mejor, cuando se observa que la mayoría de los trabajadores sociales que participan en esta investigación reconocen que, en su formación, la dimensión teórica ha sido más fuerte que la práctica investigadora. Así se entiende la valoración que tienen los profesionales que se vinculan con este perfil, del entrenamiento adquirido en la aplicación de ciertas técnicas de investigación, como entrevistas y focus groups.

A la práctica investigadora se suma su interés en evaluar y retroalimentar su quehacer. En sus testimonios, los trabajadores sociales que se asocian a este perfil, insisten en la necesidad de obtener feedback y aprender de sus errores. Consideran esenciales las experiencias de retroalimentación para su formación como investigadores, dedicando especial atención en sus testimonios, a la revisión de las experiencias de este tipo en las que han participado. De sus relatos se desprende que lo que buscan es contar con referentes y maestros, que no sólo les devuelvan la imagen de lo que hacen, sino una valoración de su práctica investigadora, lo que se constituye en un elemento clave de quienes se están formando como investigadores.

\section{Perfil tres. Profesionales de la intervención}

Como anticipamos al inicio de este artículo, los rasgos que caracterizan a este último grupo presentan mayores indefiniciones y fluctuaciones que los perfiles anteriores, por lo que su delimitación se concibe desde el inicio como un ejercicio preliminar y sujeto a revisión. Este aspecto adquiere mayor sentido cuando se consideran las trayectorias profesionales, las perspectivas y proyecciones de aquellos trabajadores sociales que se vinculan a esta categoría, y que permite incluso conside- rar que no sea un perfil propiamente tal, sino una transición entre los perfiles uno y dos ${ }^{47}$. Quienes lo conforman son profesionales en transición, en búsqueda de un nicho o espacio profesional, lo que resulta bastante coherente con la edad de sus protagonistas ${ }^{48}$.

A diferencia de los profesionales que se vinculan con el segundo perfil, estas trabajadoras sociales construyen su identidad a partir de las intervenciones sociales que desarrollan, y por lo mismo, es desde esta posición que estructuran sus aproximaciones y concepciones en torno a la investigación. Esencialmente, las trabajadoras sociales de este perfil han desarrollado su itinerario profesional vinculadas a procesos de gestión participativa e intervenciones comunitarias, con especial énfasis en el fortalecimiento o impulso de estrategias de desarrollo local y territorial. Dimensión que también se constituye en un elemento clave para poder comprender la forma como estas profesionales conciben las articulaciones entre investigación e intervención.

Las tres declaran sus intereses por un tipo de Trabajo Social más comunitario y participativo, además comparten la motivación por desarrollar un trabajo vinculados al sector público, sobre todo a nivel de municipios u otros servicios descentralizados. A futuro se visualizan asentadas en un territorio y promoviendo procesos de participación social.

Tomando en cuenta lo anterior, no resulta extraño que estas entrevistadas se refieren esencialmente a la investigación desde un enfoque que realza esta dimensión, que construye y genera conocimiento desde abajo hacia arriba, y que, por lo mismo, toma algunos de los elementos del modelo bottom-up de generación de políticas públicas (Lahera, 2002) ${ }^{49}$.

Uno de los rasgos que caracteriza a este perfil, es el hecho que estas profesionales se encuentran en búsqueda, en tránsito desde un estadio a otro. Desencadenado, en la mayoría de los casos, por la salida de la universidad, que marca el fin de la juventud y el inicio de la vida adulta. Es este proceso de búsqueda el que nos permite comprender que las integrantes de este perfil se encuentren explorando distintos ámbitos de trabajo, revisando opciones y asumiendo ciertas alternativas encaminadas a de-

47 Las protagonistas de los testimonios seis y siete formarían parte de este perfil, al igual que la protagonista del quinto testimonio, cuyo perfil mixto posee elementos comunes con el perfil dos.

48 En este grupo, la mayor de las entrevistadas tiene más de 30 años y corresponde a la profesional a quien se le ha atribuido un perfil mixto.

49 Este modelo alternativo de implementación de políticas públicas que surge en la década de los setenta se ha intensificado como modalidad de gestión, en particular en el desarrollo de programas y políticas sociales focalizados en los ámbitos de integración social, superación de la pobreza y participación social (Silva, 1996). 
limitar mejor su lugar o espacio en lo social. Lo anterior, refuerza los argumentos que lleva a definir a este perfil a partir de la búsqueda (rasgo que emergió en las primeras fases de análisis y que permaneció como una constante en el transcurso de esta investigación).

En esta exploración de un espacio profesional, la intervención aparece como un referente sustancial del cual asirse. No ocurre lo mismo con la investigación, que se observa como una experiencia ajena, que la ser rememorada les recuerda su paso por la universidad. A partir de lo anterior, se constata quela intervención se constituye en el elemento articulante del tercer perfil, donde el quehacer profesional se nutre de la labor investigativa desarrollada por otros trabajadores sociales $u$ otros profesionales.

De sus relatos autobiográficos se desprende que estas profesionales se autoconciben manejando herramientas y competencias específicas de intervención social comunitaria, adquiridas inicialmente durante su proceso de formación profesional, y luego perfeccionadas en sus experiencias laborales. La investigación formaría parte de esas herramientas profesionales (una entre otras) y desde esta perspectiva, se concibe directamente vinculada con el quehacer profesional. Principalmente se refieren a un tipo de investigación aplicada, que se emplea para analizar fenómenos y problemáticas concretas, y cuyos resultados permiten iluminar propuestas y acciones de intervención específicas.

En términos generales se puede afirmar que estos trabajadores sociales visualizan la investigación:

Como la generación de conocimientos que se orientan a la intervención: en la medida que refuerzan su importancia por los alcances que esta tiene en el conocimiento y comprensión de determinados fenómenos sociales. De una forma $\mathrm{u}$ otra, en los tres testimonios vinculados este perfil se insiste en la dimensión aplicada de la investigación, ajustándola a las necesidades de intervención. Esta visión de la investigación, estructura tanto las visiones que las profesionales tienen de la investigación, como el modo como ésta se materializa. Por lo mismo, en este perfil, es bastante claro que la investigación estaría su- bordinada (o acomodada) a la intervención ${ }^{50}$.

Dado lo anterior, no resulta extraño que estas tres profesionales asimilen y homologuen la investigación con otras estrategias profesionales como el diagnóstico social e incluso la sistematización, en la medida que las conciben como herramientas de generación de conocimiento, que conducen a un proyecto o una intervención concreta.

Como un modelo-tipo ideal: concebida como parte de este horizonte de búsqueda, el que esperan concretar a mediano plazo, dado que reconocen que su actual ejercicio profesional presenta una serie de dificultades y obstáculos, que les impiden concretar sus intereses investigativos.

En sus testimonios, la investigación es entendida como un proceso estructurado, sistemático y ordenado. Lo que deja en evidencia una determinada forma de hacer y concebir la investigación, marcada en este caso por un modelo de investigación que se desarrolla esencialmente bajo un paradigma postpositivista y donde predominan los abordajes metodológicos analítico/cuantitativos. Se reconoce la influencia de un esquema investigativo que utiliza el marco lógico, para definir y marcar las principales etapas y pasos a seguir en la investigación.

Tomando en cuenta lo anterior dan cuenta de:

Escasa práctica investigadora: Donde la investigación concebida como una tarea que se realiza en contextos específicos, principalmente académicos y distintos a los espacios laborales donde estas profesionales suelen intervenir. Sus concepciones sobre investigación se sustentan en sus escasas experiencias investigadoras, por lo general circunscritas a sus trabajos de finalización de carrera $^{51}$.

Falta de repertorios analíticos: si bien las asistentes sociales de este perfil valoran la formación obtenida en la carrera de Trabajo Social, y destacan particularmente su preparación en estadística. Reconocen que tienen limitaciones en el análisis, especialmente porque en esta fase se enfrentan a interrogantes y dilemas que no pueden responder con los esquemas y marco interpretativos en

50 Es precisamente esta concepción funcional de la investigación lo que critica el protagonista del cuarto testimonio cuando observa la secuencia que conduce a toda investigación hacia la intervención. Y ante lo cual reafirma la necesidad de pensar la investigación como un fenómeno en si mismo.

51 Con excepción de la protagonista del quinto testimonio que presenta una experiencia investigadora más amplia y vinculada con otros espacios, lo que nos vuelve a la idea de un perfil mixto entre dos y tres, más ajustado a las particularidades de esta profesional. 
los cuales fueron formadas.

Dado lo anterior, se observa que quienes integran este perfil aún no han logrado desarrollar una posición crítica respecto de la investigación social y el quehacer investigativo de la profesión. Su incipiente experiencia de investigadora, sumada a la actitud de búsqueda de un espacio profesional, las hace especialmente sensibles a cuestionamientos e interrogantes sobre este tema.

Como las trabajadoras sociales que conforman este perfil se autodefinen como novatas en materia de investigación, refuerzan constantemente la necesidad de contar con apoyos y referentes al momento de plantearse una práctica investigadora, aspecto que se constituye en una característica de este perfil ${ }^{52}$. En sus relatos autobiográficos, es significativa la existencia de ambigüedades e incertidumbres relacionadas tanto con el proceso de investigación como con la utilidad de sus resultados.

Estas profesionales suelen exponer abiertamente estas interrogantes, ampliando sus cuestionamientos a otros actores y contextos, a quienes interpelan directamente. Será precisamente esta capacidad de preguntar y preguntarse, la que forma parte de la actitud investigativa que al final de este trabajo se identifica como uno de los componentes que caracterizan a la investigación que se practica desde el Trabajo Social. En algunos casos es posible constatar que la incertidumbre y la falta de respuestas, profundiza sus búsquedas, a tal punto que las lleva a visualizar escenarios de formación o especialización que a futuro les permitan abordar sus interrogantes y preocupaciones en este ámbito.

Tras estas aproximaciones permanecen aquellas aproximaciones que conciben a la investigación como un medio o herramienta para el desarrollo profesional ${ }^{53}$. Es probable que esta concepción instrumental de la investigación esté vinculada precisamente con su escasa experiencia investigadora. $\mathrm{Y}$ que se comprende mejor cuando se observa que en sus concepciones de investigación, sólo existe como referente investigativo la tesis o tesina de grado, cuyo imaginario lleva a estos profesionales a considerar la investigación como una tarea ajena al ejercicio profesional, y más vinculada a propósito académicos-administrativos que marca el fin de los requisitos de la formación y la obtención del título profesional.

De algún modo en sus relatos, la investigación es visualizada como una tarea de dedicación exclusiva $^{54}$, y por lo mismo, difícil y poco compatible con su trabajo cotidiano. Bajo esta aproximación la investigación rivalizaría y tensionaría el quehacer profesional, dado que requiere de tiempo, conocimientos y destrezas específicas Tensión que se encuentra presente en los relatos autobiográficos de estas trabajadoras sociales a quienes les parece importante y quieren hacer investigación, pero no logran desarrollarla en sus actuales inserciones laborales. Esta falta de concreción, que surge como consecuencia de una multiplicidad de factores (donde el tiempo resulta el elemento articulante), es la que les hace pasar por el lado de la investigación, sin lograr ponerse en su camino.

A diferencia de los perfiles anteriores, en este perfil sociobiográfico, la tensión entre hacer y conocer se vuelve más evidente. Lo que lleva a que en determinados momentos, las trabajadoras sociales visualicen ambos procesos en forma separada y por caminos paralelos (no conciliables). Un ejemplo de ello, lo encontramos en la protagonista del quinto testimonio, quien declara que a futuro le gustaría dedicarse en forma exclusiva a la investigación, lo que nos recuerda que en su caso se observan rasgos de un perfil mixto, que combina elementos del segundo y tercer perfil.

En términos generales se podría decir que, por sus experiencias investigadoras, la investigación adquiere una connotación de proceso abierto, perfeccionable y en alguna medida aún por desarrollar. Pese a ello, la mayoría de las profesionales que integran este grupo tienen una visión positiva de la investigación realizada, y resulta válido suponer que en estos casos, puede haber un cambio en sus concepciones iniciales.

Tal vez por lo mismo, la mayor parte de sus de-

52 La protagonistas de los testimonio cinco y siete se refieren explícitamente a la necesidad de contar con un guía que les indique los caminos a seguir en materia de investigación, reconociendo precisamente esta cualidad en algunos profesionales con los que se ha vinculado.

53 Se considera relevante relacionar estas aproximaciones que los trabajadores sociales tienen de la investigación con la metáfora de la caja de herramienta, de la cual los profesionales van extrayendo distintas herramientas e instrumentos con usos y funciones determinadas. Metáfora que fue desarrollada por Gilles Deleuze hace más de 30 años.

54 Que se realiza cuando se dan ciertas condiciones especificas como encontrarse en la fase final de un proceso de formación o inserto laboralmente en un espacio laboral que sólo se dedique a hacer investigación. Esta última situación se asemeja bastante a las opciones laborales que se han forjado los protagonistas vinculados con el segundo perfil. 
mandas van por el lado del saber investigar en contextos distintos a los académicos, y para ello buscan referentes, esquemas y modelos que les permitan concretar este anhelo investigativo. Ante estas demandas, los marcos investigativos del enfoque cuantitativo ${ }^{55}$ parecen ofrecerles mayores garantías, lo que les lleva a dos exponentes de este perfil a reconocer sus preferencias por este tipo de aproximaciones.

Con anterioridad se ha comentado que la búsqueda de certezas y referentes constituye en un rasgo que caracteriza a este perfil y determina en buena medida sus acercamientos hacia la investigación, evidenciando que en esta posición, los trabajadores sociales suelen pedir recetas y orientaciones bastante precisas que guíen su quehacer, eviten errores y les den seguridad en un ámbito que no es visto como una fortaleza. En este caso se aprecia que la inseguridad de estas profesionales podría estar asociada al estatus de los trabajadores sociales y los imaginarios sociales que se construyen respecto de esta profesión, a la que se le atribuyen una serie de atributos y repertorios esperados, que no siempre consideran como parte del quehacer profesional el desarrollo sistemático de prácticas investigadoras ${ }^{56}$.

\section{Como hacen investigación... trazos de la investigación que se practica desde el Trabajo Social}

Situados en una posición distinta a algunas concepciones sobre los trabajadores sociales, en este artículo se asume el reconocimiento de la existencia de un oficio investigativo del Trabajo Social, y se analizan en profundidad las concepciones y prácticas investigadoras de un grupo de profesionales, que perteneciendo a una misma generación profesional, han desarrollado aproximaciones y visiones distintas de la investigación y sus posibilidades articuladoras con la intervención profesional. El análisis de los testimonios autobiográficos permitió la identificación de tres perfiles de trabajadores sociales, diferenciados a partir del modo como conciben y hacen investigación social. Como se indicó en el punto anterior, cada perfil se configura a partir de un eje o tópico central, desde el cual se despliegan elementos y rasgos específicos que le constituyen.
Más allá de los elementos que les diferencian, estos perfiles profesionales comparten aspectos $y$ perspectivas de investigación social, lo que permite evidenciar algunos rasgos y componentes esenciales que constituirían el quehacer investigativo de los trabajadores sociales. Surgen de esta forma tres dimensiones o ámbitos que se identifican como característicos de la investigación que realizan estos profesionales en tanto interpelan a un posicionamiento ético determinado, una forma articulante de relacionar investigación e intervención y al modo como estos profesionales desarrollan su formación investigadora.

La primera dimensión que ha sido denominada relación ética, se encuentra presente en la totalidad de los testimonios analizados, en la medida que interpela y aboga por el papel de los sujetos en los procesos de investigación. La segunda dimensión, menos explícita, se ha construido a partir del estudio transversal de los perfiles presentados, y da cuenta de las vinculaciones entre investigación e intervención, identificando una serie de repertorios comunes, al interior de los cuales se aglutinan una serie de técnicas e instrumentos, que operarían en ambos procesos, y que permite identificar distintas posibilidades de articulación entre intervención e investigación. La tercera dimensión observa la formación y competencias con la que los trabajadores sociales emprenden la tarea investigadora, con especial énfasis en la forma como estos profesionales van completando y actualizando sus conocimientos, así como en las limitaciones y vacíos que presentan de cara a la investigación.

Como se indicó al inicio de este artículo, estos elementos no tienen la pretensión de ser concluyentes, sino más bien buscan poner en evidencia los derroteros o lineamientos en torno a los cuales es posible continuar investigando.

La principal idea que se depura del análisis de los testimonios autobiográficos, indica que los trabajadores sociales tienden a realizar una investigación éticamente situada. Y se habla de situada, porque es explícitamente reflexiva en este punto, que conlleva un cuestionamiento acerca de las consecuencias, efectos e impactos de su trabajo investigativo. Observar que la investigación de los trabajadores sociales

55 Si bien la lógica de investigación analítica es un elemento que atraviesa a todos los entrevistados, es especialmente evidente en el caso de las profesionales que integran este perfil.

56 La necesidad de autoafirmación o validación en esta materia, podrá vincularse con la noción de identidad deteriorada desarrollada por Goffman, en su clásico trabajo Estigma (original de 1963), donde analiza los medios y mecanismos que establece la sociedad para categorizar a las personas 
conlleva un trasfondo $u$ horizonte ético, no significa que las otras profesiones no lo posean. Lo que se quiere connotar en este trabajo es que, en este tipo de profesionales, la investigación con perspectiva ética no emerge como una opción, sino que se constituye en un rasgo dominante, a tal extremo que podría llegar a concebirse como un imperativo.

En los testimonios de los profesionales se puede rastrear, con bastante claridad, el modo como esta perspectiva se va instalando desde la etapa de formación en los profesionales de Trabajo Social ${ }^{57}$ Madurando en algunos casos o quedando como una inquietud posible de profundizar. Con las interpelaciones a esta dimensión, los profesionales buscan hacer explícita las situaciones y dilemas éticos presentes en las investigaciones sociales, exponiéndola a la revisión y consideraciones de otros investigadores.

Con menos, presencia que la dimensión ética, constatamos también que los trabajadores sociales se caracterizarían por desarrollar una investigación articulada con otros contextos y realidades. Lo que se quiere explicitar en este punto son las múltiples interconexiones que los protagonistas de los testimonios, establecen entre los procesos de indagación y generación de conocimiento y las prácticas o actuaciones determinadas. Sería precisamente este carácter articulante de la investigación de los trabajadores sociales, lo que imprime un rasgo diferenciador de la investigación de otros profesionales.

Del análisis realizado se desprende que los puentes y caminos a recorrer entre investigación e intervención (entre hacer y conocer, entre teoría y práctica), tienen múltiples sentidos y no se restringen a un modo u otro. Si bien en los testimonios se observa una secuencia que resulta dominante, en la medida que define un recorrido que va de la investigación a la intervención, es posible identificar otros esquemas (distinto a los secuenciales) que avanzan en forma de espiral articulando, a veces fundiendo y otras veces separando prácticas investigativas y de intervención. La figura de una espiral ascendente, que se retroalimenta mutuamente, parece ser en este caso lo suficientemente dinámica para explicar esta complejidad articuladora que se ha querido estudiar.

En esta figura tendrían cabida tanto las visiones de los trabajadores sociales que critican el carácter instru- mental y funcional que se imprime a la investigación, como aquellas perspectivas que sólo le asignan validez a la generación de conocimiento en la medida que desemboca en una actuación concreta. También quedan contenidas, en este esquema de múltiples posibilidades, las hipótesis iniciales que sustentaron este trabajo y que planteaban desde el origen de la profesión la existencia de vasos comunicantes entre ambos procesos; así como aquellas visiones donde no es posible forma de articulación alguna.

Finalmente encontramos en la autoformación y en la actitud de indagación permanente otro de los rasgos que caracteriza el quehacer investigativo de los trabajadores sociales. Esta posición, muy marcada en las profesionales que forman parte del tercer perfil, también se encuentra presente en los otros profesionales entrevistados, quienes entienden esta búsqueda como el germen de una actitud investigadora que se irradia a distintos escenarios, incluidos los ámbitos de investigación e intervención.

En términos generales, se advierte que los profesionales de Trabajo Social generan estrategias y mecanismos diversos que les permiten completar sus necesidades de formación, especialmente en aquellos campos donde se consideran más débiles, como ocurre con las herramientas de análisis avanzado en ciencias sociales tanto en investigación cuantitativa como cualitativa. En esta dimensión formativa también resulta esencial la búsqueda de referentes y maestros que apoyen la labor investigativa, y que les permitan completar lo que les falta. De los relatos es posible colegir que de cara a la investigación, los trabajadores sociales se documentan, se informan y aprenden lo más posible. Es probable que esta autonomía formativa, surja ante la necesidad de reafirmar una identidad y capacidad investigadora, que parece cuestionada, o que ha sido concebida como una excepción cuando se observa que, mayoritariamente, los imaginarios de la profesión se encaminan hacia la intervención.

Queda aun continuar investigando acerca de las prácticas y posibilidades investigadoras de estas profesiones, que ubicadas en cualquiera de los perfiles construidos en este trabajo se manifestaron deseosas e interesadas por hacer investigación, contribuyendo tanto al mejoramiento social como al desarrollo disciplinar del Trabajo Social. En esta dirección se encaminan nuestros pasos.

57 Catalina Wainerman en su artículo "Acerca de la formación de investigadores en ciencias sociales" aborda algunas de estos elementos (en Wairnerman y Sautu, 2001). 


\section{Referencias}

ARENAL, C. (1999). La beneficencia, la filantropía y la caridad, Alicante: Miguel de Cervantes (Original de 1894)

BERTAUX, D. (1981). "From the Life-History Approach to the Transformation of Sociological Practice" in Bertaux, D. (Editor) Biography and Society. The Life History Approach in Social Sciences, California: Sage.

BERTAUX, D. (1999). "El enfoque biográfico, su validez metodológica, sus potencialidades" [Artículo] En Proposiciones Vol.29. Santiago de Chile: Ediciones SUR. Recuperado el 5 de septiembre de 2005, de http:// www.sitiosur.cl/r.php?id=1395. (Original de 1980 publicado en Cahiers lnternationaux de Sociologie, Vol. LXIX, París, pp. 197-225)

BOUFOY-BASTICK, B. (2004, January). Auto-Interviewing, Auto-Ethnography and Critical Incident Methodology for Eliciting a Self-Conceptualised Worldview [36 paragraphs]. Forum Qualitative Sozialforschung / Forum: Qualitative Social Research [On-line Journal], 5(1), Art. 37. Recuperado el 2 de febrero de 2008, de http://www.qualitative-research. net/fqs-texte/1-04/1-04boufoy-e.htm.

CÁCERES, M., OBLITAS, B. Y PARRA, L. (2000). La Entrevista en Trabajo Social, Buenos Aires: Espacio.

CALleJO, J. \& VIEDMA, A. (2005). Proyectos y estrategias de investigación social: la perspectiva de la intervención, Madrid: McGraw-Hill.

CHAMBERLAYNE, P., BORNAT, J. Y WENGRAF, T. (editor.): The Turn to Biographical Methods in Social Science. Comparative Issues and Examples. London: Routledge.

DENZIN, N. \& LINCOLN, Y. (2005). (Eds.) The Sage Handbook of Qualitative Research. Thousand Oaks: Sage (Original de 1994)

DEXTER, L. (1970). Elite and specialized interviewing, Evanston: Northwestem University Press.

GOFFMAN, E. (2003) Estigma. La Identidad deteriorada, Buenos Aires: Amorrortu (Original de 1963).

GRASSI, E. (1995). "Trabajo Social e Investigación, una relación necesaria" en Perspectivas Revista de Trabajo Social, Santiago de Chile: Ediciones Universidad Católica Blas Cañas.

HELER, M. (Coord.) (2002). Filosofía Social y Trabajo Social. Buenos Aires: Biblos.

IBÁÑEZ, J. (1994) El regreso del sujeto. La investigación social de segundo orden, Madrid, Siglo XXI (Original de 1991)

JONES, K. (2004). "Minimalist passive interviewing technique and team analysis of narrative qualitative data", in Maggs-Rapport F. (Editor) New Qualitative Methodologies in Health and Social Care. London: Routledge.
KARSZ, S. (2007). Problematizar el Trabajo Social. Definición, figuras, clínica. Barcelona: Gedisa (Original 2004).

KISNERMAN, N. (1998). Pensar el Trabajo Social, Buenos Aires: Lumen.

KORNBLIT, A. (2004). "Historias y relatos de vida: una herramienta clave en metodologías cualitativas", en Kornblit, A. (Coord.) Metodologías cualitativas en ciencias sociales, Buenos Aires: Biblos, p. 15-33.

LAHERA, E. (2002). Introducción a las políticas públicas, Santiago de Chile, Fondo de Cultura Económica.

LEJEUNE, P. (1994). El pacto autobiográfico y otros estudios, Madrid: Meazul-edymion (Original de 1975)

LEWIS, O. (1961). Antropología de la Pobreza: Cinco Familias, México: Fondo de Cultura Económica (Original de 1959)

LEWIS, O. (1964). Los hijos de Sánchez. Autobiografía de una familia mexicana, México: Fondo de Cultura Económica (Original de 1961)

MARCHEVSKY, C. (2006). El lazo social: una propuesta sobre el objeto de conocimiento en Trabajo Social, Buenos Aires: Espacio.

MARSAL, J. F. (1979). Pensar bajo el franquismo. Intelectuales y política en la generación de los años cincuenta. Barcelona: Península.

MATUS, T. (1999). Propuestas contemporáneas en Trabajo Social. Hacia una intervención polifónica, Buenos Aires: Espacio.

MATUS, T., AYLWIN, N. Y FORTTES, A. (2004) La reinvención de la memoria, Indagación sobre el proceso de profesionalización del Trabajo Social chileno 1925-1965, Santiago de Chile: Ediciones Universidad Católica.

MAZZOLA, A. (1998). "La construcción del conocimiento en Trabajo Social" en Bueno, Abad, José Ramón (Dir.) La construcción y transmisión de los saberes en el Trabajo Social, Valencia, Nau llibres, p. 84-110.

MERTON, R. \& KENDALL, P. (1946). "The focused interview", in American Journal of Sociology, Vol. 51, p. 541-547. Recuperado el 14 de junio de 2007, de http://links.jstor.org/sici?sici=0002-9602\%28194605 \%2951\%3A6\%3C541\%3ATFI\%3E2.0.CO\%3B2-A

PUJADAS, J. (2002). El método biográfico, el uso de las historias de vida en ciencias sociales, Madrid: CIS, Colección Cuadernos Metodológicos No5. (Ed.Org. 1992)

RAMOS, C. (2005). "Cómo investigan los sociólogos chilenos en los albores del siglo XXI: Paradigmas y herramientas del oficio" en Persona y Sociedad Vol ${ }^{\circ}$ XIX, No3, p. 85-119.

REED-DANAHAY, D. (1997). Auto/Ethnography. New York: Berg. 
RICHMOND, M. (2005). Diagnóstico Social, Madrid: Siglo XXI (Original de 1917)

RICHMOND, M. (1996). El caso social individual, Madrid: Talasa (Original de 1922)

ROSENTHAL, G. (2004). "Biographical Research" in Seale, C., Gobo, G.; Gubrium, J. \& Silverman, D. (Editors) Qualitative Research Practice, London: Sage

ROSELL, M. T. (1989). La entrevista en el Trabajo Social, Barcelona: Hogar del Libro.

SEDEN, J. (1999). Counselling Skills in Social Work Practice, Philadelphia: Open University Press.

SENNETT, R. (2003). El respeto. Sobre la dignidad del hombre en un mundo de desigualdad. Barcelona: Anagrama.

SCHÖN, D. (1983). The Reflexive Practitioner, New York: Basic Books.

SHÖN, D. (1987). Educating the Reflexive Practitioner, San Francisco: Jossey-Bass.

SILVA, A. (1996). Implementing Policy Innovations in Latin America: Politics, Economic and Techniques, Washington DC: Banco Mundial

SOYDAN, H. (2004): La historia de las ideas en el Trabajo Social. Valencia: Tirant Lo Blanch.

TRAVI, B. (2006). La dimensión técnico-instrumental en Trabajo Social: reflexiones y propuestas acerca de la entrevista, la observación, el registro y el informe social, Buenos Aires: Espacio.

THOMAS, W. \& ZNANIECKI, F. (2006). El Campesino polaco en Europa y en América, Madrid: CIS Clásicos del Pensamiento Social (Original de 1919)

VALLES, M. (2002). Entrevistas cualitativas Colección Cuadernos Metodológicos No32. Madrid: CIS.
VALLES, M. (2006). "Abrirse camino en el mundo de la investigación social cualitativa, desde la península ibérica, entre los milenios segundo y tercero. Testimonio personal" in Forum Qualitative Sozialforschung / Forum, Qualitative Social Research [On-line Journal], 7(4), Art. 16. Recuperado el 21 de diciembre de 2007 , de http,//www.qualitativeresearch.net/fqs-texte/406/06-4-16-s.htm.

VALLES, M. (2007 septiembre). "Metodología biográfica y experiencia migratoria: el enfoque de los testimonios anónimos y de autor en el legado y la estela de Juan F. Marsal", comunicación presentada al IX Congreso Español de Sociología de la FES, Barcelona.

VALLES, M. (2008). "Metodología biográfica y experiencia migratoria: el método de los testimonios anónimos y de autor en el legado de Juan F. Marsal", original en proceso de evaluación para su publicación en Papers.

VASS, C. (editor) (1996). Social Work Competences, London: Sage Publications.

WAINERMAN, C. (2001) "Acerca de la formación de investigadores en ciencias sociales" en Wainerman C. y Sautu, R. (Ed.) (2001) La trastienda de la investigación, Argentina: Lumiere (Original de 1997).

WENGRAF, T. (2001). Qualitative Research Interviewing: Biographic Narratives and Semi-structured Method, London: Sage.

WENGRAF, T. (2004). "Boundaries and Relationships in Homelessness Work: Lola, an Agency Manager" in Forum Qualitative Social Research 5(1), art. 13. Recuperado el 11 de junio de 2007, de http://www. qualitative-research.net/fqs-texte/1-04/1-04wengrafe.htm.

WHYTE, W. (1971). La Sociedad de las esquinas, México: Editorial Diana (Original de 1943) 